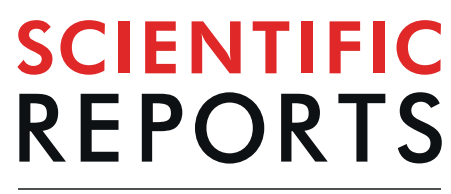

natureresearch

\title{
OPEN Proton-pump inhibitor use is associated with a broad spectrum of neurological adverse events including impaired hearing, vision, and memory
}

\author{
Tigran Makunts, Sama Alpatty, Kelly C. Lee, Rabia S. Atayee \& Ruben Abagyan* \\ Proton-pump inhibitors, PPIs, are considered effective therapy for stomach acid suppression due to \\ their irreversible inhibition of the hydrogen/potassium pump in the gastric parietal cells. They are widely \\ prescribed and are considered safe for over-the-counter use. Recent studies have shown an association \\ between PPI use and Alzheimer dementia, while others have disputed that connection. We analyzed \\ over ten million United States Food and Drug Administration Adverse Event Reporting System reports, \\ including over forty thousand reports containing PPIs, and provided evidence of increased propensity \\ for memory impairment among PPI reports when compared to histamine-2 receptor antagonist control \\ group. Furthermore, we found significant associations of PPI use with a wide range of neurological \\ adverse reactions including, migraine, several peripheral neuropathies, and visual and auditory \\ neurosensory abnormalities.
}

Proton pump inhibitors (PPIs) are drugs commonly used in treatment of acid-related disorders including gastroesophageal reflux disease, Helicobacter Pylori induced gastric ulcers, duodenal ulcer, erosive esophagitis, and Zollinger-Ellison syndrome ${ }^{1,2}$. Treatment of acid-related disorders includes antacids, PPIs, and histamine- 2 receptor antagonists (H2RAs) ${ }^{3}$. The PPIs are preferred over the H2RAs because of their superior efficacy due to their irreversible inhibition of the $\mathrm{H}+/ \mathrm{K}+\mathrm{ATPase}^{4,5}$. National Health and Nutrition Examination Survey (NHANES) revealed a rise in the number of PPI prescriptions (2.9-7.8\%) among 40-64 year old individuals from 1999 to $2012^{6}$. NHANES did not account for over-the-counter (OTC) PPI intake. The class of PPI drugs includes six Food and Drug Administration (FDA) approved medications such as rabeprazole, lansoprazole, pantoprazole, esomeprazole, omeprazole, and dexlansoprazole. The high number of the PPI prescriptions, their OTC availability, and the increased likelihood of long-term use have raised concerns over unexpected adverse reactions (ADRs). It was demonstrated that the PPI pharmacology may not be limited to local inhibition of H-K-ATPase pump in parietal cells in the stomach ${ }^{7,8}$.

Common ADRs of PPIs, observed in clinical trials, include diarrhea, nausea, vomiting, flatulence, and headache $^{9-12}$. Serious ADRs include breathing difficulty, rash, facial swelling, and throat tightness ${ }^{9-12}$. Recent studies revealed growing evidence of association with electrolyte abnormalities ${ }^{13,14}$ kidney injury $^{15,16}$, bone fractures ${ }^{17}$, Clostridium difficile-associated diarrhea ${ }^{18}$, Alzheimer disease $(\mathrm{AD})^{19}$, and non-AD type dementia ${ }^{19,20}$. However, other studies were not able to confirm the association between PPI use and a greater risk of dementia of both AD or non-AD type t1,22 $^{21}$

Dementia associated with $\mathrm{AD}$ has a substantial impact on the quality of life of the patients and their caregiv$\mathrm{ers}^{23,24}$ and on the healthcare costs ${ }^{25,26}$. AD is considered the third most costly disease in the United States, with the costs being primarily associated with long-term care in nursing facilities ${ }^{27}$.

The current lack of consensus on PPI association with $\mathrm{AD}$ and non-AD type dementia warranted further investigation and analysis of other neurological outcomes. In our study, we performed an analysis of the FDA Adverse Event Reporting System database (FAERS/AERS) and identified significant increases of AD and non-AD 


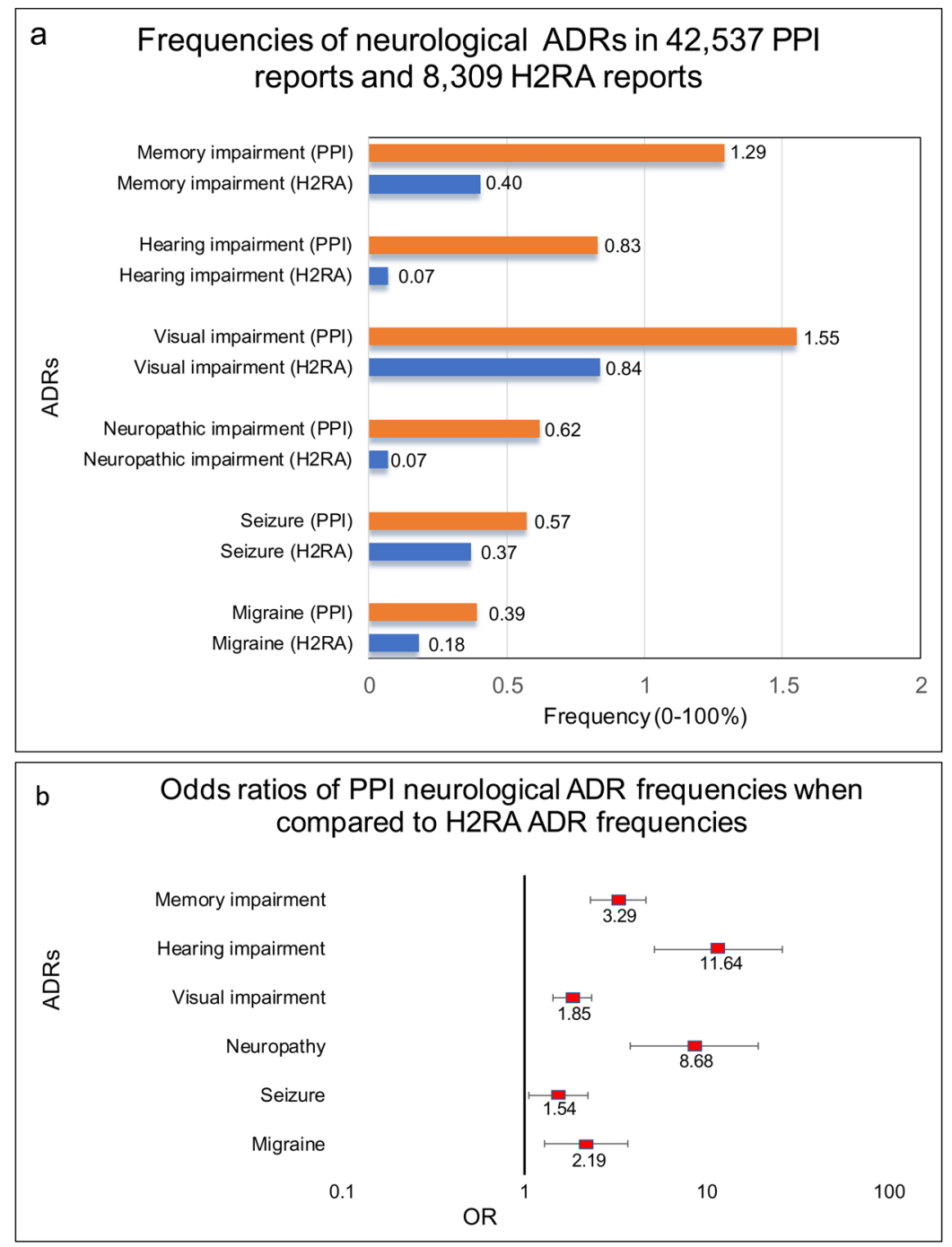

Figure 1. FAERS-reported frequencies and odds ratios of neurological/neurosensory adverse drug reactions. (a) Frequencies of neurological/neurosensory adverse events for patients in FAERS/AERS who took PPIs $(\mathrm{n}=42,537)$ and H2RAs $(\mathrm{n}=8,309)$. (b) Odds ratios were calculated comparing adverse event frequencies of PPI and H2RA patients. Ranges represent 95\% confidence intervals (95\% CI) (see Methods). A logarithmic $\mathrm{X}$-axis shows odds ratios and their confidence intervals.

dementia reports along with increased association with other types of memory impairment in PPI patients. Additionally, we found a significant increase in wide variety of peripheral neurological and neuropathic adverse events, as well as visual and auditory impairment ADRs.

\section{Results}

PPI "monotherapy" - neurological and neurosensory ADRs. Reports in which PPIs were administered with no reported concurrent medications had a significant increase in memory impairment ADRs in comparison with H2RAs reports (OR 3.28, 95\% CI [2.31, 4.67]) (Fig. 1b, Table 1). The outcomes included memory impairment, amnesia, dementia of the AD type, and non-AD dementia. Surprisingly, the H2RA cohort $(\mathrm{n}=8,309)$ had three out of four ADRs listed above, but had no single report of dementia of the AD type (Table 1$)$ while the PPI cohort $(n=42,537)$ had as many as 80 reports of the AD dementia. Interestingly, the auditory and visual ADRs followed a similar trend, with ORs being $(11.64[5.20,26.11])$ and $(1.85[1.44,2.37])$ respectively (Fig. 1b Tables 2 and 3). Neuropathic/neurological impairment ADR frequencies were also increased in the described above PPI cohort $(8.68$ [3.86, 19.49]) (Fig. 1b, Table 4). These included cranial and peripheral neuropathies, sciatica, and nerve injury as well as other neuropathic ADRs (Table 4). There was a small but significant increase in reported seizures $(1.54[1.06,2.24])$ (Fig. 1b and Table 5) and a significant increase in migraine reports in the PPI cohort $(2.19[1.29,3.72])$ (Fig. 1b and Table 6). 


\begin{tabular}{|l|l|l|}
\hline \multirow{2}{*}{ Adverse drug reaction } & PPI+ & H2RA+ \\
\cline { 2 - 3 } & $(\mathbf{n}=\mathbf{4 2 , 5 3 7 )}$ & $(\mathbf{n}=\mathbf{8 , 3 0 9 )}$ \\
\hline memory impairment & 246 & 11 \\
\hline amnesia & 152 & 11 \\
\hline dementia, Alzheimer type & 80 & 0 \\
\hline dementia, non-AD type & 72 & 11 \\
\hline total memory impairment ADRs & 550 out of 42,537 & 33 out of 8,309 \\
\hline odds ratio (95\% CI) [p value] & $\begin{array}{l}3.29(2.31 \text { to } 4.67) \\
{[p<0.0001]}\end{array}$ & \\
\hline
\end{tabular}

Table 1. Types and numbers of memory impairment (Memory impairment, amnesia, Alzheimer dementia, non-AD type dementia) related ADRs for patients on PPIs $(n=42,537)$ and H2RAs $(n=8,309)$. Odds ratios were calculated from adverse event frequencies files.

\begin{tabular}{|l|l|l|}
\hline \multirow{2}{*}{ Adverse drug reaction } & PPI+ & H2RA+ \\
\cline { 2 - 3 } & $(\mathbf{n}=\mathbf{4 2 , 5 3 7 )}$ & $(\mathbf{n = 8 , 3 0 9 )}$ \\
\hline hypoacusis & 134 & 2 \\
\hline impaired hearing & 127 & 0 \\
\hline deafness & 59 & 4 \\
\hline deafness unilateral & 20 & 0 \\
\hline sudden hearing loss & 12 & 0 \\
\hline deafness transitory & 1 & 0 \\
\hline deafness neurosensory & 1 & 0 \\
\hline deafness bilateral & 1 & 0 \\
\hline total hearing impairment ADRs & 355 out of 42,537 & 6 out of 8,309 \\
\hline odds ratio (95\% CI) [p value] & $\begin{array}{l}11.64(5.20 \text { to } 26.11) \\
{[p<0.0001]}\end{array}$ & \\
\hline & \multicolumn{2}{|l}{} \\
\hline
\end{tabular}

Table 2. Types and numbers of hearing impairment related ADRs (hypoacusis, impaired hearing, deafness, unilateral deafness, sudden hearing loss etc.) for patients on PPIs $(n=42,537)$ and H2RAs $(n=8,309)$. Odds ratios were calculated from adverse event frequencies. ADRs reported as listed in the FAERS/AERS files.

\begin{tabular}{|l|l|l|}
\hline \multirow{2}{*}{ Adverse drug reaction } & PPI+ & H2RA+ \\
\cline { 2 - 3 } & $(\mathbf{n}=\mathbf{4 2 , 5 3 7 )}$ & $(\mathbf{n}=\mathbf{8 , 3 0 9})$ \\
\hline visual impairment & 205 & 18 \\
\hline vision blurred & 204 & 33 \\
\hline blindness & 94 & 6 \\
\hline visual acuity reduced & 82 & 5 \\
\hline blindness unilateral & 34 & 1 \\
\hline visual field defect & 18 & 1 \\
\hline visual disturbance & 11 & 5 \\
\hline blindness transient & 7 & 1 \\
\hline night blindness & 2 & 0 \\
\hline sudden visual loss & 1 & 0 \\
\hline total visual impairment ADRs & 658 out of 42,537 & 70 out of 8,309 \\
\hline odds ratio (95\% CI) [p value] & $1.85(1.44$ to 2.37$)$ & \\
{$[\mathrm{p}<0.0001]$} & \\
\hline
\end{tabular}

Table 3. Reports containing ADRs related to visual impairment (visual impairment, blurred vision, blindness, reduced visual acuity, unilateral blindness etc.) for patients on PPIs $(n=42,537)$ and H2RAs $(n=8,309)$. Odds ratios and $95 \%$ confidence intervals were calculated from adverse event frequencies and numbers of reports. The ADRs terms are taken directly from the FAERS/AERS files.

\section{Methods}

FDA adverse event reporting system. The FDA Adverse Event Reporting System (FAERS/AERS) was created by the FDA to document medication error reports, product quality complaints, and medication adverse events. Physicians, pharmacists, other healthcare providers, patients, and legal representatives submit the drug-related adverse event reports through MedWatch on a voluntary basis. If the adverse event is reported to the manufacturer, the manufacturer is required by law to forward the report to the FDA FAERS system. 


\begin{tabular}{|c|c|c|}
\hline \multirow[b]{2}{*}{ Adverse drug reaction } & \multirow{2}{*}{\begin{tabular}{|l|} 
PPI+ \\
$(n=42,537)$ \\
\end{tabular}} & \multirow{2}{*}{$\begin{array}{l}\text { H2RA }+ \\
(n=8,309)\end{array}$} \\
\hline & & \\
\hline neuropathy peripheral & 74 & 4 \\
\hline nerve injury & 38 & 0 \\
\hline nerve compression & 23 & 1 \\
\hline sciatica & 21 & 0 \\
\hline neuralgia & 14 & 0 \\
\hline polyneuropathy & 12 & 0 \\
\hline optic neuritis & 8 & 0 \\
\hline hyperreflexia & 7 & 0 \\
\hline peripheral sensory neuropathy & 5 & 0 \\
\hline IV-th nerve paralysis & 5 & 0 \\
\hline VII-th nerve paralysis & 5 & 0 \\
\hline autonomic neuropathy & 4 & 0 \\
\hline peroneal nerve palsy & 4 & 0 \\
\hline neurodegenerative disorder & 3 & 0 \\
\hline areflexia & 3 & 0 \\
\hline neurological symptom & 3 & 0 \\
\hline optic ischaemic neuropathy & 3 & 0 \\
\hline neuromyopathy & 3 & 0 \\
\hline peripheral nerve injury & 3 & 0 \\
\hline sciatic nerve injury & 3 & 1 \\
\hline nerve degeneration & 2 & 0 \\
\hline trigeminal neuralgia & 2 & 0 \\
\hline cranial nerve disorder & 2 & 0 \\
\hline neuritis & 2 & 0 \\
\hline VI-th nerve paralysis & 2 & 0 \\
\hline peripheral sensorimotor neuropathy & 2 & 0 \\
\hline vagus nerve disorder & 1 & 0 \\
\hline optic neuropathy & 1 & 0 \\
\hline optic nerve injury & 1 & 0 \\
\hline nerve root compression & 1 & 0 \\
\hline nerve conduction studies abnormal & 1 & 0 \\
\hline radial nerve palsy & 1 & 0 \\
\hline neuropathy & 1 & 0 \\
\hline neuropathic arthropathy & 1 & 0 \\
\hline neurogenic bladder & 1 & 0 \\
\hline motor neuron disease & 1 & 0 \\
\hline hyporeflexia & 1 & 0 \\
\hline CIDP & 1 & 0 \\
\hline $\begin{array}{l}\text { total neuropathic/neurological } \\
\text { impairment ADRs }\end{array}$ & 265 out of 42,537 & 6 out of 8,309 \\
\hline odds ratio $(95 \% \mathrm{CI})$ [p value] & $\begin{array}{l}8.68(3.86 \text { to } 19.49) \\
{[\mathrm{p}<0.0001]}\end{array}$ & \\
\hline
\end{tabular}

Table 4. ADRs related to neurological/neuropathic impairment (neuropathy, peripheral, nerve injury, nerve compression, sciatica, neuralgia, polyneuropathy, optic neuritis, hyperreflexia, peripheral sensory neuropathy etc.) for patients on PPIs $(n=42,537)$ and H2RAs $(n=8,309)$. Abbreviations: CIDP - chronic inflammatory demyelinating polyradiculoneuropathy. Odds ratios and $95 \%$ confidence intervals were calculated from adverse event frequencies and numbers of reports. The ADRs terms are taken directly from the FAERS/AERS files.

At the time of data collection for the study, the FAERS/AERS contained over 10.3 million reports from January 2004 to March 2018. Both FAERS and AERS data sets are available online at: https://www.fda.gov/Drugs/ GuidanceComplianceRegulatoryInformation/Surveillance/AdverseDrugEffects/ucm082193.htm.

All data analysis methods and procedures were carried out in accordance with existing guidelines and regulations. Since only the publicly available data were used in the study, and the FDA data sets used had been reviewed and released, no additional institutional and/or licensing committee approval was warranted.

Combining and normalizing the FAERS/AERS reports. FAERS/AERS contains reports from the United States and other countries with their respective specific demographic formats and medication brand/ 


\begin{tabular}{|l|l|l|}
\hline \multirow{2}{*}{ Adverse drug reaction } & PPI+ & H2RA+ \\
\cline { 2 - 3 } & $(\mathbf{n}=\mathbf{4 2 , 5 3 7 )}$ & $(\mathbf{n}=\mathbf{8 , 3 0 9})$ \\
\hline convulsion & 142 & 18 \\
\hline seizure & 44 & 1 \\
\hline epilepsy & 24 & 5 \\
\hline grand mal convulsion & 10 & 2 \\
\hline status epilepticus & 9 & 2 \\
\hline petit mal epilepsy & 5 & 1 \\
\hline hypocalcaemic seizure & 4 & 0 \\
\hline generalized tonic clonic seizure & 2 & 0 \\
\hline partial seizures & 1 & 2 \\
\hline hyperglycaemic seizure & 1 & 0 \\
\hline juvenile myoclonic epilepsy & 1 & 0 \\
\hline clonic convulsion & 1 & 0 \\
\hline total seizure ADRs & 244 out of 42,537 & 31 out of 8,309 \\
\hline odds ratio (95\% CI) [p value] & 1.54 (1.06 to 2.24) & \\
\hline
\end{tabular}

Table 5. Types and numbers of seizure related ADRs (convulsion, seizure, epilepsy, grand mal convulsion, status epilepticus etc.) for patients on PPIs $(n=42,537)$ and H2RAs $(n=8,309)$. Odds ratios were calculated from adverse event frequencies. ADRs reported as listed in FAERS/AERS files.

\begin{tabular}{|l|l|l|}
\hline \multirow{2}{*}{ Adverse drug reaction } & PPI+ & H2RA+ \\
\cline { 2 - 3 } & $(\mathbf{n}=\mathbf{4 2 , 5 3 7 )}$ & $(\mathbf{n}=\mathbf{8 , 3 0 9})$ \\
\hline migraine & 163 & 14 \\
\hline migraine with aura & 4 & 1 \\
\hline ophthalmoplegic migraine & 1 & 0 \\
\hline total migraine ADRs & 168 out of 42,537 & 15 out of 8,309 \\
\hline Odds ratio (95\% CI) [p value] & $\begin{array}{l}2.19(1.29 \text { to } 3.72) \\
\text { [p=0.0036] }\end{array}$ & \\
\hline
\end{tabular}

Table 6. ADRs related to migraine (migraine, migraine with aura, ophthalmoplegic migraine) for patients on PPIs $(n=42,537)$ and H2RAs $(n=8,309)$. Odds ratios and $95 \%$ confidence intervals were calculated from adverse event frequencies and numbers of reports. The ADRs terms are taken directly from the FAERS/AERS files.

generic names. Before the data collection and analysis online drug databases were utilized to create a dictionary with all of the varieties of drug brand names to translate them into generic names. FAERS/AERS quarterly report sets of seven files vary and their format had been changed at some point. To make the data sets more homogeneous, each quarterly report set of files was downloaded in dollar-separated text format (.txt) and modified to standardize the fields. Missing columns in the FAERS/AERS data set were added with no values to create a standard data table with over 10.3 million adverse event reports.

Study outcomes. There were 20,317 uniquely worded ADRs reported to FAERS and AERS. ADRs were grouped into generalized categories of study outcomes: (1) memory impairment (memory impairment, amnesia, dementia Alzheimer type, dementia), (2) neuropathy (neuropathy peripheral, nerve injury, nerve compression, sciatica, neuralgia, polyneuropathy, optic neuritis, hyperreflexia, peripheral sensory neuropathy, IV-th nerve paralysis, VII-th nerve paralysis, autonomic neuropathy, peroneal nerve palsy, neurodegenerative disorder, areflexia, neurological symptom, optic ischaemic neuropathy, neuromyopathy, peripheral nerve injury, sciatic nerve injury, nerve degeneration, trigeminal neuralgia, cranial nerve disorder, neuritis, VI-th nerve paralysis, peripheral sensorimotor neuropathy, vagus nerve disorder, optic neuropathy, optic nerve injury, nerve root compression, nerve conduction studies abnormal, radial nerve palsy, neuropathy, neuropathic arthropathy, neurogenic bladder, motor neuron disease, hyporeflexia, and chronic inflammatory demyelinating polyradiculoneuropathy), (3) visual impairment (visual impairment, vision blurred, blindness, visual acuity reduced, blindness unilateral, visual field defect, visual disturbance, blindness transient, night blindness, and sudden visual loss), (4) hearing impairment (hypoacusis, impaired hearing, deafness, deafness unilateral, sudden hearing loss, deafness transitory, deafness neurosensory and deafness bilateral),(5) migraine (migraine, migraine with aura, and ophthalmoplegic migraine), and (6) seizure (convulsion, seizure, epilepsy, grand mal convulsion, status epilepticus, petit mal epilepsy, hypocalcemic seizure, generalized tonic-clonic seizure, partial seizures, hyperglycemic seizure, juvenile myoclonic epilepsy, and clonic convulsion). 


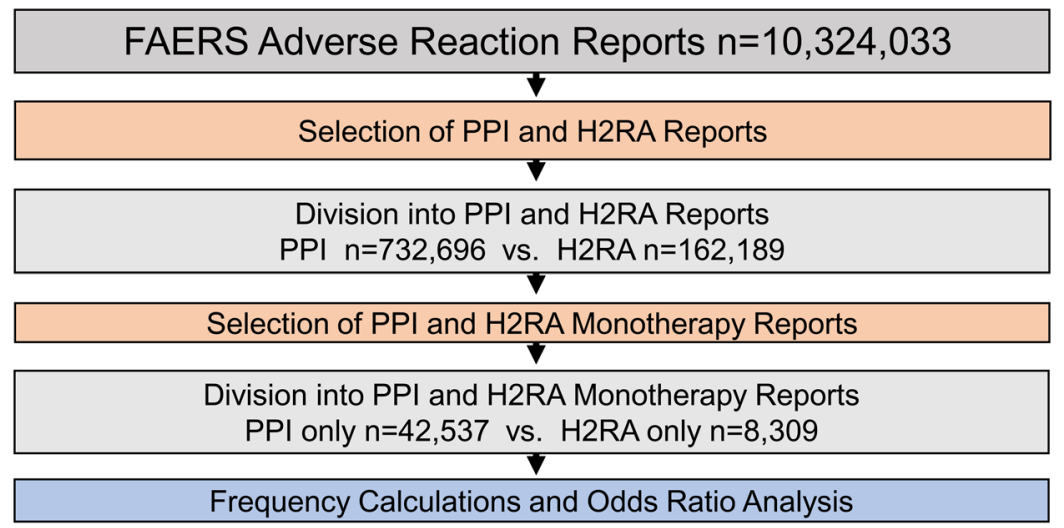

Figure 2. Legend: Flowchart of inclusion, exclusion and cohort selection for adverse event comparison between PPI and H2RA"monotherapy" reports.

\begin{tabular}{|c|c|c|c|c|c|c|}
\hline Sex & $\begin{array}{l}\text { PPI reports } \\
(n=42,537)\end{array}$ & Frequency $(\%)$ & $\begin{array}{l}\text { H2RA reports } \\
(n=8,309)\end{array}$ & Frequency (\%) & P-value & $\begin{array}{l}\% \\
\text { Difference }\end{array}$ \\
\hline Female & 25116 & 59.69 & 4579 & 57.68 & $<0.001$ & 2.01 \\
\hline Male & 12000 & 28.52 & 2710 & 34.14 & $<0.001$ & 5.62 \\
\hline Unreported & 4963 & 11.79 & 650 & 8.19 & $<0.001$ & 3.61 \\
\hline \multicolumn{7}{|l|}{ Age difference } \\
\hline Mean age, years (SD) & $58.3(15.9)$ & & $55.6(20.1)$ & & $<0.001$ & 2.7 \\
\hline Median age & 58.6 & & 59.7 & & $<0.001$ & 1.1 \\
\hline Unreported (\%) & 45.4 & & 55.1 & & & \\
\hline
\end{tabular}

Table 7. Reported patient demographics in PPI and H2RA "monotherapy" cohorts.

Cohort choice. For the PPI cohort $(n=732,696)$, out of 10,324,033 records, reports where rabeprazole, lansoprazole, pantoprazole, omeprazole and esomeprazole and dexlansoprazole were selected excluding reports with ranitidine, famotidine, cimetidine, and nizatidine concurrent use. For the H2RA cohort $(\mathrm{n}=162,189)$, reports where ranitidine, famotidine, cimetidine, and nizatidine were used, excluding concurrent PPI use. The cohorts were further narrowed down to "monotherapy" reports. This assignment was defined when a submitted report contained a single PPI or a single H2RA medication. For that reason, any confounding concurrent medications and associated comorbidities were not applicable. Resulting cohorts consisted of 42,537 PPI reports and 8,309 H2RA reports (Fig. 2). ADR frequencies for both cohorts were calculated, and odds ratio analysis was performed by dividing their relative ADR frequencies and calculating the $95 \%$ confidence intervals of the OR values. The cohort choice was validated by strongly overlapping distributions of demographic parameters (Tables 7 and 8 ).

Statistical analysis. Descriptive statistics. Frequencies for each studied side effect (Fig. 1a) was calculated by the equation:

$$
\text { Frequency }=(\text { nReports with } \mathrm{ADR} \text { in a cohort }) /(\text { nReports in a cohort }) * 100
$$

Comparative Statistics. ADR report rates were compared via the Odds Ratio (OR) analysis for Fig. $1 \mathrm{~b}$ and Tables 1-6 using the following equations:

$$
\mathrm{OR}=(\mathrm{a} / \mathrm{b}) /(\mathrm{c} / \mathrm{d})
$$

where

a. Number of cases in exposed group with an adverse event.

b. Number of cases in exposed group with no adverse event.

c. Number of cases in control group with the adverse event.

d. Number of cases in control group with no adverse event.

$$
\mathrm{LnOR}=\operatorname{Ln}(\mathrm{OR})
$$

Standard Error of Log Odds Ratio; 


\begin{tabular}{|c|c|c|c|c|c|c|}
\hline Country & $\begin{array}{l}\text { No. of PPI } \\
\text { reports }\end{array}$ & Frequency \% & $\begin{array}{l}\text { No. of H2RA } \\
\text { reports }\end{array}$ & Frequency \% & $\%$ difference & $\begin{array}{l}>1 \% \\
\text { Different }\end{array}$ \\
\hline United States & 37139 & 88.26 & 6928 & 87.27 & 0.99 & \\
\hline Great Britain & 1122 & 2.67 & 177 & 2.23 & 0.44 & \\
\hline Japan & 472 & 1.12 & 382 & 4.81 & 3.69 & $*$ \\
\hline Germany & 357 & 0.85 & 24 & 0.3 & 0.55 & \\
\hline France & 330 & 0.78 & 29 & 0.37 & 0.42 & \\
\hline Canada & 309 & 0.73 & 22 & 0.28 & 0.46 & \\
\hline Italy & 312 & 0.74 & 39 & 0.49 & 0.25 & \\
\hline Brazil & 282 & 0.67 & 3 & 0.04 & 0.63 & \\
\hline Turkey & 173 & 0.41 & 13 & 0.16 & 0.25 & \\
\hline Australia & 151 & 0.36 & 7 & 0.09 & 0.27 & \\
\hline China & 149 & 0.35 & 9 & 0.11 & 0.24 & \\
\hline Denmark & 143 & 0.34 & 4 & 0.05 & 0.29 & \\
\hline Spain & 138 & 0.33 & 13 & 0.16 & 0.16 & \\
\hline Nederlands & 103 & 0.24 & 34 & 0.43 & 0.18 & \\
\hline Sweden & 52 & 0.12 & 6 & 0.08 & 0.05 & \\
\hline Singapore & 48 & 0.11 & 9 & 0.11 & 0 & \\
\hline Belgium & 41 & \begin{tabular}{|l|}
0.1 \\
\end{tabular} & 9 & 0.11 & 0.02 & \\
\hline New Zealand & 42 & 0.1 & 3 & 0.04 & 0.06 & \\
\hline Chile & 28 & 0.07 & 3 & 0.04 & 0.03 & \\
\hline India & 15 & 0.04 & 15 & 0.19 & 0.15 & \\
\hline Costa Rica & 30 & 0.07 & 0 & 0 & 0.07 & \\
\hline Unknown & 198 & 0.47 & 45 & 0.57 & 0.1 & \\
\hline
\end{tabular}

Table 8. PPI and H2RA “monotherapy" report frequencies by country of origin.

$$
\mathrm{SE}_{\mathrm{LnOR}}=\sqrt{ }(1 / \mathrm{a}+1 / \mathrm{b}+1 / \mathrm{c}+1 / \mathrm{d})
$$

95\% Confidence Interval;

$$
95 \% \mathrm{CI}=\left[\exp \left(\mathrm{LnOR}-1.96 \times \mathrm{SE}_{\mathrm{LnOR}}\right), \exp \left(\mathrm{LnOR}+1.96 \times \mathrm{SE}_{\mathrm{LnOR}}\right)\right]
$$

\section{Discussion}

In our study, we analyzed a large number of ADR reports concerning patients taking only a single treatment of either a PPI and an H2RA drug using the FAERS/AERS databases, and quantified the association between PPI exposure and memory impairments, a wide range of neuropathies, visual and auditory impairments, migraines, and seizures.

Memory impairment related ADRs. Using data from the German Study on Aging, Cognition and Dementia in Primary Care Patients 75 years and older, Haenisch et al. found that PPIs users were at increased risk of dementia (Hazard Ratio (HR) 1.38, 95\% CI, [1.04-1.83]) and AD (HR, 1.44, 95\% CI, [1.01, 2.06]) compared to non-users ${ }^{19}$. A later study lead by Gomm et al. analyzed data from the German statutory health insurer, Allgemeine Ortskrankenkassen (AOK) and observed a significantly increased risk of dementia (HR, 1.44, 95\% $\mathrm{CI},[1.36,1.52], \mathrm{p}<0.001)$ in older adults using PPIs ${ }^{20}$. In contrast, Goldstein et al. ${ }^{21}$ analyzed data from Tertiary Academic Alzheimer Disease Centers and found that continuous and intermittent PPIs use was not associated with increased risk of dementia or $\mathrm{AD}^{21}$. In our study, we were not able to quantify the risk of AD-type dementia by itself since the H2RA cohort had zero reports of AD-type dementia and the PPI cohort had eighty reports. We included $\mathrm{AD}$-type dementia in the generalized memory impairment cohort which included $\mathrm{AD}$ and non-AD type dementia, memory impairment and amnesia. We found a significant increase in memory impairment ADRs (OR $3.28,95 \%$ CI $[2.31,4.67])$ in the PPI cohort (Fig. 1b, Table 1). Memory impairment ADRs were helpful to capture possible early symptoms leading to dementia.

Neuropathies. No large-scale clinical study has previously established a direct correlation of PPI use with neuropathies, including peripheral and poly-neuropathy, nerve injury and compression, sciatica, and neuralgia. Surprisingly, we identified a significant increase of neuropathy reports in patients taking only PPIs when compared to patients taking only H2RAs (OR 8.68, 95\% CI $[3.86,19.49]$ ). This observation was statistically significant, and clinically relevant. While our study did not address the molecular mechanism of action leading to neuropathies, a possible mechanism may involve Vitamin B12. An increased gastric $\mathrm{pH}$ level has been found to correlate with decreased Vitamin B12 levels ${ }^{28-30}$. In turn, B12 deficiency has been associated with reversible peripheral neuropathy and spinal cord degeneration and mental status alteration ${ }^{31,32}$. There are not many case reports depicting a direct correlation of PPI use with peripheral neuropathies ${ }^{33,34}$. While the direct correlation with PPI use and peripheral neuropathies had been noticed in a few case studies, we established an over eight-fold increase in broader range of neuropathy reports in a cohort of 42,537 PPI patients when compared to 8,309 H2RA patients. 
Hearing impairment. While a recent prospective study established an association between hearing loss with gastroesophageal reflux disease (GERD) ${ }^{35}$, no correlation with a specific antacid drug class was established. Furthermore, the study associated the hearing loss with the disease itself and suggested that PPI use may be beneficial for auditory ADRs. In other studies, the association between GERD and hearing problems was explained by the mid ear exposure to gastric acid in young patients with otitis media ${ }^{36,37}$. Contrary to these findings, our analysis showed a significant increase in risk of hearing impairment (OR $11.6495 \%$ CI [5.20, 26.11]) specific to PPI-containing reports. This observation could not be explained by gastroesophageal disorders alone. Moreover, if this assumption were true, the hearing impairment risk would have been expected to be higher in the H2RA cohort since PPIs have superior efficacy in $\mathrm{pH}$ control. Thus, our finding supports a possible different mechanism in which the hearing impairment ADRs may be affected by the drug treatment and not the disease alone.

Visual impairment. There have been many published case reports of visual impairment, including blurred vision $^{38}$, ocular damage, optic neuropathy and blindness, associated with PPI use ${ }^{39,40}$. However, a retrospective cohort study of 94,063 patients, did not find an association between patients who took omeprazole or H2RAs (cimetidine, famotidine, nizatidine, ranitidine) and visual impairment ${ }^{41}$. In our analysis we divided the treated patients into two groups, compared their ADRs (42,537 PPI reports vs. 8,309 H2RA reports) and found an increased risk of visual impairment in patients taking PPIs (OR 1.85, 95\% CI [1.44, 2.37]). This large-scale data analysis supports the initial case studies and provides a possible explanation the negative results of García Rodríguez et al. study in which PPI- and H2RA-treated patients were in a mixed cohort.

Migraine. Associations between PPI use and headache were established in the clinical trials of all the approved PPIs $^{9}$, but there were no reports specific to migraine which is associated with a higher burden on quality of life ${ }^{42,43}$.

The headache association was confirmed in a crossover study conducted in Taiwan where lansoprazole and esomeprazole use increased headache incidence (OR, 1.20, 95\% CI, [1.07,1.35], P $<0.002)^{44}$. However, according to our findings the headache effect may be common to both treatment classes, since there was no significant difference in headache reports between PPI and H2RA cohorts. Surprisingly the migraine report frequencies were different between the cohorts. We observed a significant increase in migraine reports in the PPI monotherapy cohort (OR 2.19, 95\% CI $[1.29,3.72])$. To our knowledge this is the first study showing association between PPI use and risk of migraine.

Seizures, convulsions, and epilepsy. An earlier observational cohort study found no association between PPI use and seizure risk in the overall population or in patients with epilepsy. In contrast, the study did find an increased risk of seizures in H2RA users ${ }^{45}$. On the other hand, in a few case reports the PPIs were found to be associated with seizures, and the authors attributed the seizure to PPI induced hypomagnesemia and hypocalcemia (electrolyte abnormalities known to influence neuronal function) ${ }^{46-48}$. Our analysis confirmed a small but significant association of PPI use with seizure-related ADRs (OR 1.54 95\% CI [1.06, 2.24]) (Fig. 1b and Table 5).

Practical implications. The observed risk of memory impairment, neuropathy, hearing and visual impairment, seizures as well as migraines with PPIs warrant a more careful consideration when selecting this class of medications for patients who already have or may be at high risk for these adverse effects, in particular, if the treatment exceeds the recommended duration limit of two or three weeks. Given these ADR observations and the availability of alternatives to PPIs for related conditions, the risk versus benefit should be carefully considered before initiating a PPI. When clinically indicated, PPIs should only be used for the duration recommended by FDA and not exceed it. The latter may be difficult to enforce because of the OTC availability of some PPIs. Additionally, other medications that may exacerbate these ADRs should be avoided when patients are prescribed PPIs. Long-term use of PPIs beyond eight weeks can be considered in individual cases as long as the benefits continue to outweigh the risks. During PPI treatment, patients should be educated about potential ADRs and advised to contact the prescriber if they suspect any of the ADRs listed above.

\section{Conclusion}

This is the first large-scale postmarketing study to show significant association between PPI monotherapy and neurological and neurosensory ADRs. Further prospective clinical trials should evaluate the neurological and sensory ADRs. In the meantime, caution and awareness of these potential ADRs are recommended. H2RAs and other treatment modalities may be considered in patients at high risk for developing memory impairment, neuropathy, hearing and visual impairment, or migraines.

Study limitations. Since FAERS and AERS reporting is voluntary, the data set represents only a subset of actual cases and therefore the FAERS/AERS ADR frequencies should not be confused with absolute population incidences. FAERS/AERS reporting can be biased by newsworthiness, and scientific and legal variables ${ }^{49,50}$. Recent studies have shown that some adverse events in the FDA database are significantly underreported ${ }^{49,51}$. An acceptable way to deal with this issue was to use Odds Ratios with 95\% CI between two cohorts instead of relying on ADR frequencies in a single cohort. Other limitations stem from the occasionally missing demographic variables, treatment dose and duration, and lack of comprehensive medical record data.

Although the study design was modeled to exclude potential confounding factors by selecting monotherapy reports, some concurrent medications and comorbidities may be also underreported, which in turn may affect the PPI and H2RA cohort composition and statistical analysis. Despite the fact that in clinical and community practice medicine reconciliation is becoming increasingly implemented, accounting for over-the-counter medication and supplement use still remains a significant unknown variable as it relies on patient self-reporting. This variable is a limitation at all the levels of clinical research from case studies to most controlled clinical trials. This is an association study where the physiological mechanism of the ADRs cannot be derived from the records. The causality of the ADRs cannot be inferred from association alone. 
Received: 16 May 2019; Accepted: 30 October 2019;

Published online: 21 November 2019

\section{References}

1. Song, H., Zhu, J. \& Lu, D. Long-term proton pump inhibitor (PPI) use and the development of gastric pre-malignant lesions. Cochrane Database Syst Rev, CD010623, https://doi.org/10.1002/14651858.CD010623.pub2 (2014).

2. Londong, W. et al. Dose-related healing of duodenal ulcer with the proton pump inhibitor lansoprazole. Aliment Pharmacol Ther $\mathbf{5}$, 245-254 (1991)

3. Katz, P. O., Gerson, L. B. \& Vela, M. F. Guidelines for the diagnosis and management of gastroesophageal reflux disease. Am J Gastroenterol 108, 308-328; quiz 329, https://doi.org/10.1038/ajg.2012.444 (2013).

4. Clissold, S. P. \& Campoli-Richards, D. M. Omeprazole. A preliminary review of its pharmacodynamic and pharmacokinetic properties, and therapeutic potential in peptic ulcer disease and Zollinger-Ellison syndrome. Drugs 32, 15-47 (1986).

5. Walan, A. et al. Effect of omeprazole and ranitidine on ulcer healing and relapse rates in patients with benign gastric ulcer. $N$ Engl $J$ Med 320, 69-75, https://doi.org/10.1056/NEJM198901123200201 (1989).

6. Kantor, E. D., Rehm, C. D., Haas, J. S., Chan, A. T. \& Giovannucci, E. L. Trends in Prescription Drug Use Among Adults in the United States From 1999-2012. JAMA 314, 1818-1831, https://doi.org/10.1001/jama.2015.13766 (2015).

7. Shin, J. M. \& Sachs, G. Pharmacology of proton pump inhibitors. Curr Gastroenterol Rep 10, 528-534 (2008).

8. Shin, J. M., Munson, K., Vagin, O. \& Sachs, G. The gastric HK-ATPase: structure, function, and inhibition. Pflugers Arch 457, 609-622, https://doi.org/10.1007/s00424-008-0495-4 (2009).

9. Prilosec (omeprazole) Label - FDA, https://www.accessdata.fda.gov/drugsatfda_docs/label/2012/019810s096lbl.pdf (2012).

10. Prevacid (lansoprazole) Label - FDA, https://www.accessdata.fda.gov/drugsatfda_docs/label/2012/020406s078-021428s025lbl.pdf (2012).

11. Nexium (esomeprazole magnesium) Label - FDA, https://www.accessdata.fda.gov/drugsatfda_docs/label/2014/ 022101s014021957s017021153s050lbl.pdf (2014).

12. Protonix (pantoprazole sodium) Label - FDA, https://www.accessdata.fda.gov/drugsatfda_docs/label/2012/020987s045lbl.pdf (2012)

13. Hardy, P. et al. Inhibition of gastric secretion by omeprazole and efficiency of calcium carbonate on the control of hyperphosphatemia in patients on chronic hemodialysis. Artif Organs 22, 569-573 (1998).

14. Makunts, T., Cohen, I. V., Awdishu, L. \& Abagyan, R. Analysis of postmarketing safety data for proton-pump inhibitors reveals increased propensity for renal injury, electrolyte abnormalities, and nephrolithiasis. Scientific Reports 9, 2282, https://doi. org/10.1038/s41598-019-39335-7 (2019).

15. Lazarus, B. et al. Proton Pump Inhibitor Use and the Risk of Chronic Kidney Disease. JAMA Intern Med 176, 238-246, https://doi. org/10.1001/jamainternmed.2015.7193 (2016).

16. Xie, Y. et al. Proton Pump Inhibitors and Risk of Incident CKD and Progression to ESRD. J Am Soc Nephrol 27, 3153-3163, https:// doi.org/10.1681/ASN.2015121377 (2016).

17. Wilson, C. Bone: proton-pump inhibitors and fractures. Nat Rev Endocrinol 8, 625, https://doi.org/10.1038/nrendo.2012.170 (2012).

18. Janarthanan, S., Ditah, I., Adler, D. G. \& Ehrinpreis, M. N. Clostridium difficile-associated diarrhea and proton pump inhibitor therapy: a meta-analysis. Am J Gastroenterol 107, 1001-1010, https://doi.org/10.1038/ajg.2012.179 (2012).

19. Haenisch, B. et al. Risk of dementia in elderly patients with the use of proton pump inhibitors. Eur Arch Psychiatry Clin Neurosci 265 , 419-428, https://doi.org/10.1007/s00406-014-0554-0 (2015).

20. Gomm, W. et al. Association of Proton Pump Inhibitors With Risk of Dementia: A Pharmacoepidemiological Claims Data Analysis. JAMA Neurol 73, 410-416, https://doi.org/10.1001/jamaneurol.2015.4791 (2016).

21. Goldstein, F. C. et al. Proton Pump Inhibitors and Risk of Mild Cognitive Impairment and Dementia. J Am Geriatr Soc 65, 1969-1974, https://doi.org/10.1111/jgs.14956 (2017).

22. Booker, A., Jacob, L. E., Rapp, M., Bohlken, J. \& Kostev, K. Risk factors for dementia diagnosis in German primary care practices. Int Psychogeriatr 28, 1059-1065, https://doi.org/10.1017/S1041610215002082 (2016).

23. Lawton, M. P. Quality of life in Alzheimer disease. Alzheimer Dis Assoc Disord 8(Suppl 3), 138-150 (1994).

24. Lawton, M. P., Brody, E. M. \& Saperstein, A. R. A controlled study of respite service for caregivers of Alzheimer's patients. Gerontologist 29, 8-16 (1989).

25. Mount, C. \& Downton, C. Alzheimer disease: progress or profit? Nat Med 12, 780-784, https://doi.org/10.1038/nm0706-780 (2006).

26. Castro, D. M., Dillon, C., Machnicki, G. \& Allegri, R. F. The economic cost of Alzheimer's disease: Family or public health burden? Dement Neuropsychol 4, 262-267, https://doi.org/10.1590/S1980-57642010DN40400003 (2010).

27. Dharmarajan, T. S. \& Gunturu, S. G. Alzheimer's disease: a healthcare burden of epidemic proportion. Am Health Drug Benefits 2, 39-47 (2009)

28. Heidelbaugh, J. J. Proton pump inhibitors and risk of vitamin and mineral deficiency: evidence and clinical implications. Ther Adv Drug Saf 4, 125-133, https://doi.org/10.1177/2042098613482484 (2013).

29. Valuck, R. J. \& Ruscin, J. M. A case-control study on adverse effects: H2 blocker or proton pump inhibitor use and risk of vitamin B12 deficiency in older adults. J Clin Epidemiol 57, 422-428, https://doi.org/10.1016/j.jclinepi.2003.08.015 (2004).

30. Lam, J. R., Schneider, J. L., Zhao, W. \& Corley, D. A. Proton pump inhibitor and histamine 2 receptor antagonist use and vitamin B12 deficiency. JAMA 310, 2435-2442, https://doi.org/10.1001/jama.2013.280490 (2013).

31. McCombe, P. A. \& McLeod, J. G. The peripheral neuropathy of vitamin B12 deficiency. J Neurol Sci 66, 117-126 (1984).

32. Sakly, G., Hellara, O., Trabelsi, A. \& Dogui, M. [Reversible peripheral neuropathy induced by vitamin B12 deficiency]. Neurophysiol Clin 35, 149-153, https://doi.org/10.1016/j.neucli.2005.12.001 (2005).

33. Rajabally, Y. A. \& Jacob, S. Neuropathy associated with lansoprazole treatment. Muscle Nerve 31, 124-125, https://doi.org/10.1002/ mus.20155 (2005).

34. Wang, A. K., Sharma, S., Kim, P. \& Mrejen-Shakin, K. Hypomagnesemia in the intensive care unit: Choosing your gastrointestinal prophylaxis, a case report and review of the literature. Indian J Crit Care Med 18, 456-460, https://doi.org/10.4103/09725229.136075 (2014)

35. Lin, B. M. et al. Prospective Study of Gastroesophageal Reflux, Use of Proton Pump Inhibitors and H2-Receptor Antagonists, and Risk of Hearing Loss. Ear Hear 38, 21-27, https://doi.org/10.1097/AUD.0000000000000347 (2017).

36. McCoul, E. D. et al. A prospective study of the effect of gastroesophageal reflux disease treatment on children with otitis media. Arch Otolaryngol Head Neck Surg 137, 35-41, https://doi.org/10.1001/archoto.2010.222 (2011).

37. O'Reilly, R. C. et al. The role of gastric pepsin in the inflammatory cascade of pediatric otitis media. JAMA Otolaryngol Head Neck Surg 141, 350-357, https://doi.org/10.1001/jamaoto.2014.3581 (2015).

38. Trevisani, S. \& Cereda, J. M. Blurred vision: a rare secondary effect of proton pump inhibitors. Rev Med Suisse 8(811-812), 814 (2012).

39. Kohno, M. et al. Two cases of ocular damage associated with proton pump inhibitors. Nihon Shokakibyo Gakkai Zasshi 97, 575-579 (2000).

40. Schönhöfer, P. S., Werner, B. \& Tröger, U. Ocular damage associated with proton pump inhibitors. BMJ 314, 1805 (1997).

41. García Rodríguez, L. A., Mannino, S. \& Wallander, M. A. Ocular safety of antiulcer drugs. Lancet 345, 1059-1060 (1995). 
42. Malone, C. D., Bhowmick, A. \& Wachholtz, A. B. Migraine: treatments, comorbidities, and quality of life, in the USA. J Pain Res 8 , 537-547, https://doi.org/10.2147/JPR.S88207 (2015).

43. Monzón, M. J. \& Láinez, M. J. Quality of life in migraine and chronic daily headache patients. Cephalalgia 18, 638-643, https://doi. org/10.1111/j.1468-2982.1998.1809638.x (1998).

44. Liang, J. F. et al. Proton pump inhibitor-related headaches: a nationwide population-based case-crossover study in Taiwan. Cephalalgia 35, 203-210, https://doi.org/10.1177/0333102414535114 (2015).

45. Sáez, M. E. et al. Risk of seizure associated with use of acid-suppressive drugs: An observational cohort study. Epilepsy Behav 62, 72-80, https://doi.org/10.1016/j.yebeh.2016.06.039 (2016).

46. Gandhi, N. Y., Sharif, W. K., Chadha, S. \& Shakher, J. A patient on long-term proton pump inhibitors develops sudden seizures and encephalopathy: an unusual presentation of hypomagnesaemia. Case Rep Gastrointest Med 2012, 632721, https://doi. org/10.1155/2012/632721 (2012).

47. Milman, S. \& Epstein, E. J. Proton pump inhibitor-induced hypocalcemic seizure in a patient with hypoparathyroidism. Endocr Pract 17, 104-107, https://doi.org/10.4158/EP10241.CR (2011).

48. Arulanantham, N., Anderson, M., Gittoes, N. \& Ferner, R. E. A 63-year-old man with hypomagnesaemia and seizures. Clin Med (Lond) 11, 591-593 (2011).

49. Alatawi, Y. M. \& Hansen, R. A. Empirical estimation of under-reporting in the U.S. Food and Drug Administration Adverse Event Reporting System (FAERS). Expert Opin Drug Saf 16, 761-767, https://doi.org/10.1080/14740338.2017.1323867 (2017).

50. Maciejewski, M. et al. Reverse translation of adverse event reports paves the way for de-risking preclinical off-targets. Elife 6, https:// doi.org/10.7554/eLife.25818 (2017).

51. Sakaeda, T., Tamon, A., Kadoyama, K. \& Okuno, Y. Data mining of the public version of the FDA Adverse Event Reporting System. Int J Med Sci 10, 796-803, https://doi.org/10.7150/ijms.6048 (2013).

\section{Acknowledgements}

We thank Chris Edwards and Da Shi for contributions to processing the FAERS/AERS data files and supporting the computer environment. We also thank Dr. Isaac V. Cohen for useful discussions.

\section{Author contributions}

T.M. performed the experiments, R.A., R.S.A., K.C.L., S.A. and T.M. designed the study and, R.A., R.S.A., K.C.L., S.A. and T.M. drafted the manuscript and reviewed the final version. R.A. processed the data set.

\section{Competing interests}

Dr. Lee is a consultant for Takeda and Otsuka America Pharmaceutical, Inc. Other authors declare no conflict of financial or non-financial interest.

\section{Additional information}

Correspondence and requests for materials should be addressed to R.A.

Reprints and permissions information is available at www.nature.com/reprints.

Publisher's note Springer Nature remains neutral with regard to jurisdictional claims in published maps and institutional affiliations.

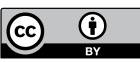

Open Access This article is licensed under a Creative Commons Attribution 4.0 International License, which permits use, sharing, adaptation, distribution and reproduction in any medium or format, as long as you give appropriate credit to the original author(s) and the source, provide a link to the Creative Commons license, and indicate if changes were made. The images or other third party material in this article are included in the article's Creative Commons license, unless indicated otherwise in a credit line to the material. If material is not included in the article's Creative Commons license and your intended use is not permitted by statutory regulation or exceeds the permitted use, you will need to obtain permission directly from the copyright holder. To view a copy of this license, visit http://creativecommons.org/licenses/by/4.0/.

(C) The Author(s) 2019 